\title{
Genetic Variation in FABP4 and Evaluation of Its Effects on Beef Cattle Fat Content
}

\author{
Daniel E. Goszczynski ${ }^{a}$, Juliana Papaleo-Mazzucco ${ }^{\mathrm{b}}$, María V. Ripoli ${ }^{\mathrm{a}}$, Edgardo L. Villarreal ${ }^{\mathrm{b}}$, \\ Andrés Rogberg-Muñoz ${ }^{a}$, Carlos A. Mezzadra ${ }^{b}$, Lilia M. Melucci ${ }^{b}$ and Guillermo Giovambattista ${ }^{a}$
}

aIGEVET - Instituto de Genética Veterinaria "Ing. Fernando Noel Dulout" (UNLP-CONICET LA PLATA), Facultad de Ciencias Veterinarias UNLP, La Plata, Argentina; ' Unidad Integrada INTA Balcarce, Facultad de Ciencias Agrarias, Universidad Nacional de Mar del Plata (UNMdP), Balcarce, Argentina

\begin{abstract}
FABP4 is a protein primarily expressed in adipocytes and macrophages that plays a key role in fatty acid trafficking and lipid hydrolysis. FABP4 gene polymorphisms have been associated with meat quality traits in cattle, mostly in Asian breeds under feedlot conditions. The objectives of this work were to characterize FABP4 genetic variation in several worldwide cattle breeds and evaluate possible genotype effects on fat content in a pasture-fed crossbred (Angus-Hereford-Limousin) population. We re-sequenced 43 unrelated animals from nine cattle breeds (Angus, Brahman, Creole, Hereford, Holstein, Limousin, Nelore, Shorthorn, and Wagyu) and obtained 22 single nucleotide polymorphisms (SNPs) over 3,164 bp, including four novel polymorphisms. Haplotypes and linkage disequilibrium analyses showed a high variability. Five SNPs were selected to perform validation and association studies in our crossbred population. Four SNPs showed well-balanced allele frequencies (minor frequency $>0.159$ ), and three showed no significant deviations from Hardy-Weinberg proportions. SNPs showed significant effects on backfat thickness and fatty acid composition $(P<0.05)$. The protein structure of one of the missense SNPs was analyzed to elucidate its possible effect on fat content in our studied population. Our results revealed a possible blockage of the fatty acid binding site by the missense mutation.
\end{abstract}

\section{KEYWORDS}

ALBP; beef; fatty acid;

meat quality; SNPs
Fat deposition has been reported as one of the most economically important traits in livestock. Variations in fat concentration contribute to several meat properties (1), affecting its quality and value. Intramuscular fat (IMF) and subcutaneous fat (backfat) are two of the main fat depots in livestock. IMF content and composition are significantly associated with the sensory and nutritional properties of beef (2), partly because of the effect of mono-unsaturated fatty acids (MUFAs), especially oleic acid, on the melting point, which influences beef flavor and tenderness (3). Fatty acid composition also has substantial implications for human health, since saturated fatty acids (SFA) are considered to cause harmful cardiovascular effects (4). On the other hand, MUFAs reduce the circulating concentration of LDL-cholesterol (5). Nowadays, much of the genetic basis that regulates fat deposition is well known, hence genetic control of this process may be possible through favorable alleles in key positions of the genes involved in the pathway (6). Fatty acid binding protein 4 (FABP4, Chromosome 14), also known as ALBP, is a functional and positional candidate gene for IMF, carcass weight, and fatty acid composition in beef cattle $(7,8)$. The protein encoded by this gene is a cytoplasmic protein that binds long-chain fatty acids and other hydrophobic ligands. It plays many roles such as uptake, transport, and hydrolysis, and is expressed primarily in adipocytes (9). The uptake of fatty acids is essential to trigger preadipocyte differentiation and terminal differentiationrelated gene expression since these fatty acids act as signal molecules (10). FABP4 also participates in lipid hydrolysis by interacting with hormone-sensitive lipase (LIPE, HSL) (11).

The FABP4 gene has been largely studied over the last few years. It has been shown to present SNP associations with marbling, subcutaneous fat depth and fatty acid composition, mostly in Asian breeds under feedlot conditions $(7,8,12-16)$. However, these results may not be necessarily comparable with studies performed under other feeding conditions, such as pasture. In this sense, different specific metabolic pathways governed by different genes may be activated by these two feeding

CONTACT D. E. Goszczynski dgoszczynski@fcv.unlp.edu.ar @ IGEVET - Instituto de Genética Veterinaria, "Ing. Fernando Noel Dulout" (UNLP-CONICET La Plata), Facultad de Ciencias Veterinarias, Universidad Nacional de La Plata (UNLP), Av. 60 y 118 S/N, La Plata B1900AVW, CC296, Buenos Aires, Argentina. Color versions of one or more of the figures in the article can be found online at www.tandfonline.com/labt.

(4) Supplemental data for this article can be accessed on the publisher's website.

(c) 2016 Taylor \& Francis 
conditions. Furthermore, much of the beef exported around the world is produced on pasture-based systems, as is the case of Argentina, Brazil, New Zealand, Paraguay, and Uruguay, among other countries (17).

All these features make FABP4 an important candidate gene for meat quality. Thus, the aims of this study were to characterize the variability of this gene across several cattle breeds with different meat quality, validate some of the genetic variants in a pasture-fed crossbred (Angus-Hereford-Limousin) population and evaluate their association with IMF, backfat thickness (BT), and fatty acid composition. Results should help improve meat quality by complementing other methods of genetic improvement.

\section{Material and methods}

\section{Animal samples and DNA extraction}

Two groups of samples were collected for this study. The first group comprised blood samples from 43 unrelated purebred animals (Angus, 5; Brahman, 5; Creole, 5; Hereford, 5; Holstein, 5; Limousin, 4; Nelore, 4; Shorthorn, 5; Wagyu, 5). It was used to characterize FABP4 genetic variation among the different breeds and get an overview of the polymorphism distribution. The second group comprised 260 steers (15-29 month-old), born between 2006 and 2010, and was used to perform population analyses, including SNP validation and association studies. This group of animals had been previously used to evaluate crossbreeding systems under pasture grazing with strategic supplementation at the Experimental Station of the National Institute of Agricultural Technology (INTA, Balcarce, Argentina). Steers included: purebred Angus (A, $\mathrm{n}=44)$ and Hereford $(\mathrm{H}, \mathrm{n}=26)$ steers, their crossbreeds $\mathrm{F} 1$ and $\mathrm{F} 2(1 / 2 \mathrm{~A} 1 / 2 \mathrm{H}, \mathrm{n}=95)$, their reciprocal backcrosses $(3 / 4 \mathrm{~A} 1 / 4 \mathrm{H}$ and $3 / 4 \mathrm{H} 1 / 4 \mathrm{~A}, \mathrm{n}=54)$, and steers produced by mating Limousin (L) sires to $\mathrm{F} 1$ crossbred cows $(1 / 2 \mathrm{~L} 1 / 4 \mathrm{~A} 1 / 4 \mathrm{H}, \mathrm{n}=41)$ (Table S1). In total, 54 sires were used, including 17 A (1-16 steers), $18 \mathrm{H}$ (1-11 steers), 8 AH (1-7 steers), 8 HA (1-7 steers), and $4 \mathrm{~L}$ (1-34 steers). L sires were mated only with F1-1/2A1/2H cows and some of the $\mathrm{A}$ and $\mathrm{H}$ sires were mated with more than one genetic group every year. The animals grazed sown pasture (predominantly Lolium multiflorum, Dactylis glomerata, Bromus catarthicus, Trifolium repens, and Trifolium pratense) and were slaughtered in eight groups. Then, meat blocks were taken from the 13th rib to perform association studies. The decision to sample this experimental population instead of other commercial populations was based on the availability of reliable information in terms of phenotypic data, management, and genetic background of the animals.

DNA was isolated from blood lymphocytes using Wizard Genomic DNA purification kit (Promega, Madison, WI, USA) following the supplier's instructions, and from meat samples as previously described by Giovambattista et al. (18).

\section{Resequencing study of the bovine FABP4 gene}

Four pairs of primers were designed according to the sequence available at GenBank (Gene ID: 281759, AC_000171.1) to amplify the coding regions of the gene by PCR in the 43 unrelated samples (Table S2). Amplification products were purified with polyethylene glycol 8000 and sequenced in an automatic DNA sequencer MegaBACE 1000 (GE Healthcare, USA), using DYEnamic ET Terminator Kit (GE Healthcare). Raw sequences were edited using Sequence Analyser (GE Healthcare) and genetic variations were identified by direct comparison with the bovine reference sequence.

\section{SNP selection and genotyping}

Five SNPs (rs110652478, rs110757796, rs110383592, rs111014258, and rs41729173) presenting variation in A, H, L, or close breeds were selected from the resequencing study and/or previous reports to perform association studies in our pasture-fed crossbred population $(\mathrm{N}=260)$. SNP rs41729173, a non-coding variant, was located approximately $1500 \mathrm{bp}$ downstream of the re-sequenced region, but had been previously shown to affect meat quality in another L-crossbred population (19). Therefore, despite this SNP was absent in the re-sequencing study, it was considered for genotyping. The other four variants had been shown to affect meat quality in Asian breeds under feedlot conditions $(12-14,16,20)$; as a result, we considered them in order to test these effects on our European population under pasture feeding.

Genotyping of the 260 samples was performed by Neogen genotyping service (USA, www.neogen.com) using the Sequenom platform (www.sequenom.com).

\section{Meat quality measurement}

Fatty acid content was measured in blocks of meat obtained from the 260 animals of the crossbred population. These blocks, corresponding to the Longissimus dorsi muscle (13th rib) were extracted from the carcass 24 hours after slaughter. Prior to slaughter, animal weight and BT were measured. Ultrasound measurements of BT were made between the 12th and 13th ribs 
with an ultrasound Aquila Pro Vet (Esaote, Genoa, Italy), with a $3.5 \mathrm{MHz}$ linear transducer and a guide of silicones that adapted the transducer to the curvature of the back of the animal using vegetable oil as coupling agent. IMF and fatty acid composition were then measured as described by Goszczynski et al. (21). The measured fatty acids were: myristic acid (C14:0);, myristoleic acid (C14:1), palmitic acid (C16:0), palmitoleic acid (C16:1), stearic acid (C18:0), oleic acid (C18:1 cis-9), linoleic acid (C18:2 cis-9,12), total SFA, total MUFA, and proportion between omega- 6 and omega3 fatty acids $(\Omega 6 / \Omega 3)$. C20:0 and other long-chain fatty acids were not included in the analysis since their percentages were lower than $0.5 \%$. The means, standard deviations, and minimum and maximum values of all these measurements are presented in Table S3.

\section{Statistical analysis and association with meat quality}

Allele frequencies, Hardy-Weinberg equilibrium (HWE), unbiased expected $\left(h_{e}\right)$ and observed $\left(h_{o}\right)$ heterozygosity, haplotypes, and linkage disequilibrium (LD) among SNPs were estimated and visualized on HAPLOVIEW v4.2 (22).

The association of genotypes with BT, IMF, and fatty acid composition was evaluated using mixed models. BT and IMF were analyzed using the following model:

$$
\begin{aligned}
Y_{i j k l}= & \mu+G G_{j}+S G_{k}+a Z 1_{i}+d Z 2_{i}+\beta W_{i}+S_{l} \\
& +e_{i j k l}
\end{aligned}
$$

where $Y_{i j k l}$ is observed value of the phenotypic variable, $\mu$ is intercept, $G G_{j}$ is fixed effect of the $\mathrm{j}^{\text {th }}$ genetic group, $S G_{k}$ is fixed effect of the $\mathrm{k}^{\text {th }}$ slaughter group, $a$ is additive effect for the SNP, $Z 1_{i}$ is incidence variable for the additive effect ( 0 for one of the homozygous genotypes, 1 for the heterozygous genotype, and 2 for the alternative homozygous one), $d$ is dominant effect for the SNP, $Z 2_{i}$ is incidence variable for the dominance effect (0 for both of the homozygous genotypes and 1 for the heterozygous genotype), $\beta W_{i}$ is animal weight covariate for the $\mathrm{i}^{\text {th }}$ animal, $S_{l}$ is random effect of the $\mathrm{l}^{\text {th }}$ sire, and $e_{i j k l}$ is random error. The same single trait model was used for fatty acid composition variables, but using ether extract instead of animal weight as covariate.

All statistical analyses were performed using the MIXED procedure of $\mathrm{SAS}^{\oplus}$ software. After all the individual SNP-trait-tests were performed, the false discovery rate (FDR) for multiple comparisons was controlled through the Benjamini and Hochberg method (23). When the additive or dominance effects of the SNP were statistically significant $(\mathrm{P}<0.05)$, the substitution effect $(\alpha)$ was calculated considering the frequencies of the major and minor alleles ( $p$ and $q$, respectively), with the following equation (24):

$$
\alpha=a+d(q-p)
$$

The variance explained by the SNP $\left(\sigma_{S N P}^{2}\right)$ was also estimated for each SNP-trait test as follows:

$$
\sigma_{S N P}^{2}=100(\mathrm{RMS}-\mathrm{FMS}) / \mathrm{RMS}
$$

where RMS is the residual of the reduced model (SNP effect excluded) and FMS is the residual of the full model (SNP effect included).

\section{Structural modeling}

In order to analyze the effects of the missense SNPs on the protein structure, 3D modeling studies were performed using HHpred (25). The protein structure of bovine FABP4 was predicted according to a high resolution model of the human FABP4 protein (3q61_A) available at the Protein Data Bank (PDB) (E-value $=4 \mathrm{E}-53)$. In addition, the protein structure was also predicted considering the human protein $\mathrm{P} 2$, a fatty acid-binding protein expressed in vertebrate peripheral nerve myelin, as template. Additionally, the effects of synonymous variations were analyzed through changes in the codon frequencies according to data available at the Codon Usage Database (http://www.kazusa.or.jp/codon/cgi-bin/ showcodon. . gi? species=9913).

\section{Results}

\section{Resequencing study}

The re-sequencing study showed 22 single nucleotide variants, including four novel SNPs (Table 1). Two of these novel SNPs (ss1751108600 and ss1751108601) were located in the promoter region of the gene. The first was detected in Angus and the other in the Zebuine breeds (Nelore and Brahman). The third novel SNP, ss1751108602, was detected in the 5' UTR region in Creole, Limousin, and Nelore. The fourth, ss1751108603, was detected in the 3' UTR region in Angus and Holstein.

The eighteen remaining variants had already been reported in the database and showed a wide distribution among breeds. Interestingly, all these SNPs showed genetic variability in Taurine cattle. Only two missense and two synonymous variants were detected, as most of the SNPs were located in non-coding (11) and intronic (7) regions. Of the 22 mutations detected in this work, 6 were in the promoter region, 1 in the 5' UTR, 4 in coding regions, 3 in the 3 ' UTR, and 8 in intronic regions. 
Table 1. Genetic variants detected in the bovine FABP4 gene by resequencing samples from nine different cattle breeds.

\begin{tabular}{|c|c|c|c|c|c|}
\hline SNP ID & Region & Type & Monomorphic breeds (AA) & $\begin{array}{l}\text { Monomorphicbreeds } \\
\text { (BB) }\end{array}$ & Polymorphic breeds \\
\hline ss1751108600 & Promoter & Noncoding & $\begin{array}{l}\text { Brahman, Creole, Hereford, Holstein, } \\
\text { Limousin, Shorthorn, Wagyu }\end{array}$ & - & Angus \\
\hline rs133198078 & Promoter & Noncoding & Holstein & $\begin{array}{l}\text { Brahman, Limousin, } \\
\text { Shorthorn }\end{array}$ & $\begin{array}{l}\text { Angus, Creole, Hereford, Nelore, } \\
\text { Wagyu }\end{array}$ \\
\hline rs132781285 & Promoter & Insertion -/G & - & - & $\begin{array}{l}\text { Angus, Creole Hereford, } \\
\text { Shorthorn, Wagyu }\end{array}$ \\
\hline ss1751108601 & Promoter & Noncoding & $\begin{array}{l}\text { Angus, Creole, Hereford, Holstein, } \\
\text { Limousin, Shorthorn, Wagyu }\end{array}$ & Brahman, Nelore & - \\
\hline rs110055647 & Promoter & Noncoding & Holstein & Limousin & Angus, Creole, Hereford \\
\hline rs109682576 & Promoter & Noncoding & Holstein & Limousin & Angus, Creole, Hereford \\
\hline ss1751108602 & UTR5 $^{\prime}$ & Noncoding & Angus, Brahman, Hereford, Holstein & $\begin{array}{l}\text { Creole, Limousin, } \\
\text { Shorthorn }\end{array}$ & Nelore, Wagyu \\
\hline rs382376907 & Intron 1 & Noncoding & $\begin{array}{l}\text { Brahman, Creole, Holstein, Nelore, } \\
\text { Wagyu }\end{array}$ & - & Angus, Hereford, Limousin \\
\hline rs109316505 & Intron 1 & Noncoding & Brahman, Wagyu, Nelore & Limousin & Angus, Creole, Hereford, Holstein \\
\hline rs110757796 & Exon 2 & Missense (I/V) & Brahman, Nelore, Creole, Limousin & - & $\begin{array}{l}\text { Angus, Hereford, Holstein, } \\
\text { Wagyu }\end{array}$ \\
\hline rs134173517 & Intron 2 & Noncoding & Creole, Holstein, Wagyu & - & Brahman, Hereford, Limousin \\
\hline rs109014985 & Intron 2 & Noncoding & Limousin, Wagyu & Creole & Brahman, Hereford, Holstein \\
\hline rs110652478 & Exon 3 & Missense (V/M) & Creole, Hereford, Limousin, Brahman & - & Holstein, Wagyu \\
\hline rs110383592 & $\begin{array}{l}\text { Exon 3- Splicing } \\
\text { Region }\end{array}$ & Synonymous & Holstein, Wagyu & Creole, Hereford & Brahman, Limousin \\
\hline rs109388335 & Intron 3 & Noncoding & Brahman & $\begin{array}{l}\text { Creole, Limousin, } \\
\text { Wagyu }\end{array}$ & Hereford, Holstein \\
\hline rs109346428 & Intron 3 & Noncoding & Creole, Wagyu & Limousin, Brahman & Hereford, Holstein \\
\hline rs111014258 & Intron 3 & Noncoding & Nelore, Brahman & $\begin{array}{l}\text { Holstein, Shorthorn, } \\
\text { Wagyu }\end{array}$ & $\begin{array}{l}\text { Angus, Creole, Hereford, } \\
\text { Limousin }\end{array}$ \\
\hline rs110370032 & Exon 4 & Synonymous & Nelore, Limousin, Shorthorn & - & $\begin{array}{l}\text { Angus, Brahman, Creole, } \\
\text { Hereford, Holstein, Wagyu }\end{array}$ \\
\hline rs109077068 & UTR3' & Noncoding & $\begin{array}{l}\text { Angus, Creole, Holstein, Nelore, } \\
\text { Shorthorn }\end{array}$ & - & $\begin{array}{l}\text { Brahman, Hereford, Limousin, } \\
\text { Wagyu }\end{array}$ \\
\hline ss1751108603 & UTR3' & Noncoding & $\begin{array}{l}\text { Brahman, Creole, Hereford, Limousin, } \\
\text { Nelore, Shorthorn, Wagyu }\end{array}$ & - & Angus, Holstein \\
\hline rs110266999 & UTR3' & Noncoding & Nelore, Shorthorn, Wagyu & - & $\begin{array}{l}\text { Angus, Brahman, Creole, } \\
\text { Hereford, Holstein, Limousin }\end{array}$ \\
\hline rs109593774 & Downstream & Noncoding & Holstein, Nelore, Shorthorn, Wagyu & Brahman & $\begin{array}{l}\text { Angus, Creole, Hereford, } \\
\text { Limousin }\end{array}$ \\
\hline
\end{tabular}

Note: Novel SNPs are indicated in bold. Association studies were then conducted with the underlined SNPs.

Twelve of the variants were transitions, nine were transversions, and one was an INDEL (single insertion).

The haplotypes and LD studies showed high variability. Several haplotypes with frequencies varying from 0.08 to 0.765 and six small linkage blocks were observed. These blocks were mostly composed of two SNPs and were quite dispersed along the gene (Fig. 1).

\section{Statistical analysis}

SNP rs110652478, a missense mutation (V/M) that showed variability in Holstein samples of the re-sequencing study, turned out to be monomorphic in the pure Angus group and showed low variability in the $75 \%$ Angus group (minor allele frequency, $\mathrm{MAF}=0.05$ ). The remaining SNPs showed well-balanced allele frequencies (MAF $>0.159$ ) across populations (Table 2).

According to the HWE test, three of the SNPs (rs41729173, rs111014258, and rs110383592) showed no significant deviations from the theoretical proportions. On the other hand, rs110652478 and rs110757796 showed significant deviations in the whole population and the $1 / 2 \mathrm{~A} 1 / 2 \mathrm{H}$ group, respectively (Table 3). Excepting rs110652478, $\mathrm{h}_{\mathrm{e}}$ ranged from 0.271 (rs41729173 in A) to 0.499 (rs110757796 in $1 / 2 \mathrm{~A} 1 / 2 \mathrm{H}$ ), and $\mathrm{h}_{\mathrm{o}}$ ranged from 0.273 (rs41729173 in A) to 0.600 (rs111014258 and rs1 10383592 in $3 / 4 \mathrm{~A} 1 / 4 \mathrm{H})$.

Four of the five analyzed SNPs were part of a linkage block, which was represented by five haplotypes. The haplotype frequencies ranged from 0.04 to 0.37 , and three of them constituted more than $85 \%$ of the haplotypes (Fig. 2). The LD study showed that SNPs rs111014258 and rs110383592 were completely linked within our population.

\section{Association study}

When analyzed individually, four of the SNPs showed significant associations with different quality traits, namely, SNP rs41729173 with MUFA $(\mathrm{P}=0.043)$; rs110383592 with $\mathrm{C} 14: 1 \quad(\mathrm{P}=0.037), \quad \Omega 6 / \Omega 3$ $(\mathrm{P}=0.011)$, and BT $(\mathrm{P}=0.040)$; rs111014258 was completely linked to rs110383592, thus sharing its effects; and rs110757796 significantly affected C14:1 


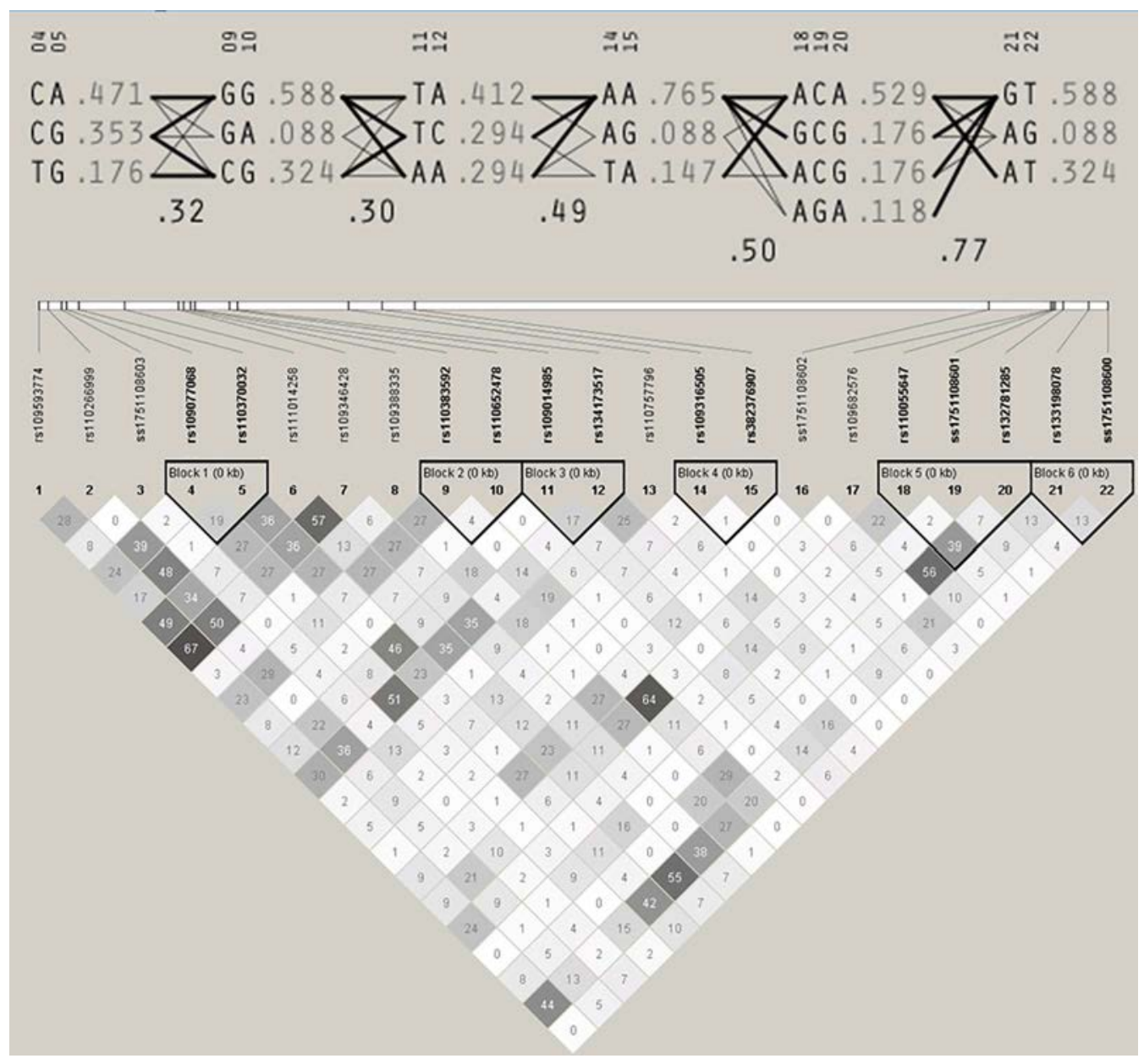

Figure 1. Haplotypes and LD in the FABP4 gene estimated from 43 unrelated samples belonging to nine different cattle breeds. Blocks are indicated with thick lines and $r 2$ values are shown inside the boxes.

$(\mathrm{P}=0.035)$ and $\mathrm{BT}(\mathrm{P}=0.011)$ (Table 4). No significant effects were observed for SNP rs110652478. Despite the associations obtained in this first approach, none of the effects remained significant when the FDR for multiple comparisons was controlled, as none of them reached the significance threshold corresponding to 48 tests.

Table 2. Allele frequencies for SNPs rs110652478, rs110757796, rs110383592, rs111014258, and rs41729173 in each group and the whole population (global).

\begin{tabular}{|c|c|c|c|c|c|c|c|}
\hline \multirow[b]{2}{*}{ Locus } & \multirow[b]{2}{*}{ A } & \multirow[b]{2}{*}{$\mathrm{H}$} & \multirow[b]{2}{*}{$3 / 4 \mathrm{~A}^{1} / 4 \mathrm{H}$} & \multicolumn{2}{|c|}{ Population } & \multirow[b]{2}{*}{$1 / 2 \mathrm{~L} 1 / 4 \mathrm{~A} 1 / 4 \mathrm{H}$} & \multirow[b]{2}{*}{ Global } \\
\hline & & & & $3 / 4 \mathrm{H} 1 / 4 \mathrm{~A}$ & $1 / 2 \mathrm{~A} 1 / 2 \mathrm{H}$ & & \\
\hline \multicolumn{8}{|c|}{ rs41729173 } \\
\hline C & 84.09 & 59.62 & 71.43 & 70.83 & 71.05 & 68.75 & 71.79 \\
\hline G & 15.91 & 40.38 & 28.57 & 29.17 & 28.95 & 31.25 & 28.21 \\
\hline \multicolumn{8}{|c|}{ rs111014258 } \\
\hline C & 63.64 & 26.92 & 40.00 & 41.67 & 40.86 & 30.49 & 41.67 \\
\hline $\mathrm{T}$ & 36.36 & 73.08 & 60.00 & 58.33 & 59.14 & 69.51 & 58.33 \\
\hline \multicolumn{8}{|c|}{ rs110383592 } \\
\hline C & 63.64 & 26.92 & 40.00 & 41.67 & 40.96 & 30.49 & 41.70 \\
\hline \multirow{2}{*}{\multicolumn{8}{|c|}{ rs110652478 }} \\
\hline & & & & & & & \\
\hline A & - & 23.08 & 5.00 & 14.58 & 13.68 & 25.61 & 13.27 \\
\hline G & 100.00 & 76.92 & 95.00 & 85.42 & 86.32 & 74.39 & 86.73 \\
\hline \multicolumn{8}{|c|}{ rs110757796 } \\
\hline A & 31.82 & 74.00 & 58.33 & 58.33 & 54.26 & 65.00 & 54.86 \\
\hline G & 68.18 & 26.00 & 41.67 & 41.67 & 45.74 & 35.00 & 45.14 \\
\hline $\mathrm{N}$ & 44 & 26 & 30 & 24 & 95 & 41 & 260 \\
\hline
\end{tabular}

Note: N: sample size; A: Angus; H: Hereford; 3/4A1/4H: 75\% Angus steers; 3/4H1/4A: 75\% Hereford steers; 1/2A1/2H: 50\% Angus 50\% Hereford steers; 1/2L1/4A1/4H: Limousin-crossbred steers. 
Table 3. Unbiased expected heterozygosity (he), observed heterozygosity (ho), and Hardy-Weinberg equilibrium p-value (HWE p-value) for rs110652478, rs110757796, rs110383592, rs111014258, and rs41729173 in each group and the whole population (global).

\begin{tabular}{|c|c|c|c|c|c|c|c|c|c|c|c|c|}
\hline \multirow[b]{2}{*}{ SNP } & \multicolumn{3}{|c|}{ A } & \multicolumn{3}{|c|}{$\mathrm{H}$} & \multicolumn{3}{|c|}{$3 / 4 \mathrm{~A}^{1} / 4 \mathrm{H}$} & \multicolumn{3}{|c|}{$3 / 4 \mathrm{H} 1 / 4 \mathrm{~A}$} \\
\hline & $\mathrm{h}_{\mathrm{e}}$ & $\mathrm{h}_{\mathrm{o}}$ & HWE $p$-value & $h_{e}$ & $h_{o}$ & HWE p-value & $\mathrm{h}_{\mathrm{e}}$ & $\mathrm{h}_{\mathrm{o}}$ & HWE p-value & $\mathrm{h}_{\mathrm{e}}$ & $\mathrm{h}_{\mathrm{o}}$ & HWE p-value \\
\hline rs41729173 & 0.27 & 0.27 & 1.00 & 0.49 & 0.50 & 1.00 & 0.42 & 0.50 & 0.38 & 0.42 & 0.33 & 0.34 \\
\hline rs111014258 & 0.47 & 0.41 & 0.51 & 0.40 & 0.38 & 1.00 & 0.49 & 0.60 & 0.26 & 0.50 & 0.42 & 0.67 \\
\hline rs110383592 & 0.47 & 0.41 & 0.52 & 0.40 & 0.38 & 1.00 & 0.49 & 0.60 & 0.26 & 0.50 & 0.42 & 0.67 \\
\hline rs110652478 & - & - & - & 0.36 & 0.15 & $0.01 *$ & 0.10 & 0.03 & 0.05 & 0.25 & 0.12 & $0.04^{*}$ \\
\hline \multirow[t]{3}{*}{ rs110757796 } & 0.44 & 0.32 & 0.08 & 0.39 & 0.36 & 0.64 & 0.49 & 0.50 & 1.00 & 0.50 & 0.33 & 0.20 \\
\hline & \multicolumn{3}{|c|}{$1 / 2 \mathrm{~A} 1 / 2 \mathrm{H}$} & \multicolumn{3}{|c|}{$1 / 2 \mathrm{~L} 1 / 4 \mathrm{~A}^{1} / 4 \mathrm{H}$} & \multicolumn{3}{|c|}{ Global } & & & \\
\hline & $\mathrm{h}_{\mathrm{e}}$ & $\mathrm{h}_{\mathrm{o}}$ & HWE p-value & $\mathrm{h}_{\mathrm{e}}$ & $\mathrm{h}_{\mathrm{o}}$ & HWE p-value & $\mathrm{h}_{\mathrm{e}}$ & $\mathrm{h}_{\mathrm{o}}$ & HWE p-value & & & \\
\hline rs41729173 & 0.41 & 0.43 & 0.80 & 0.43 & 0.52 & 0.27 & 0.41 & 0.42 & 0.85 & & & \\
\hline rs111014258 & 0.49 & 0.47 & 0.83 & 0.43 & 0.46 & 0.72 & 0.49 & 0.46 & 0.93 & & & \\
\hline rs110383592 & 0.49 & 0.47 & 1.00 & 0.43 & 0.46 & 0.72 & 0.49 & 0.46 & 0.94 & & & \\
\hline rs110652478 & 0.24 & 0.06 & $<0.01^{*}$ & 0.39 & 0.12 & $<0.01^{*}$ & 0.23 & 0.07 & $<0.01^{*}$ & & & \\
\hline rs110757796 & 0.50 & 0.36 & 0.05 & 0.46 & 0.40 & 0.49 & 0.50 & 0.37 & 0.08 & & & \\
\hline
\end{tabular}

\section{Structural analysis}

In this work, rs110757796 affected myristoleic acid content. As this SNP had been reported to affect fatty acid composition in Asian cattle by acting specifically on palmitic and palmitoleic acid contents $(12,14)$, we decided to predict and analyze the possible structural effects of this mutation to provide a reasonable explanation for

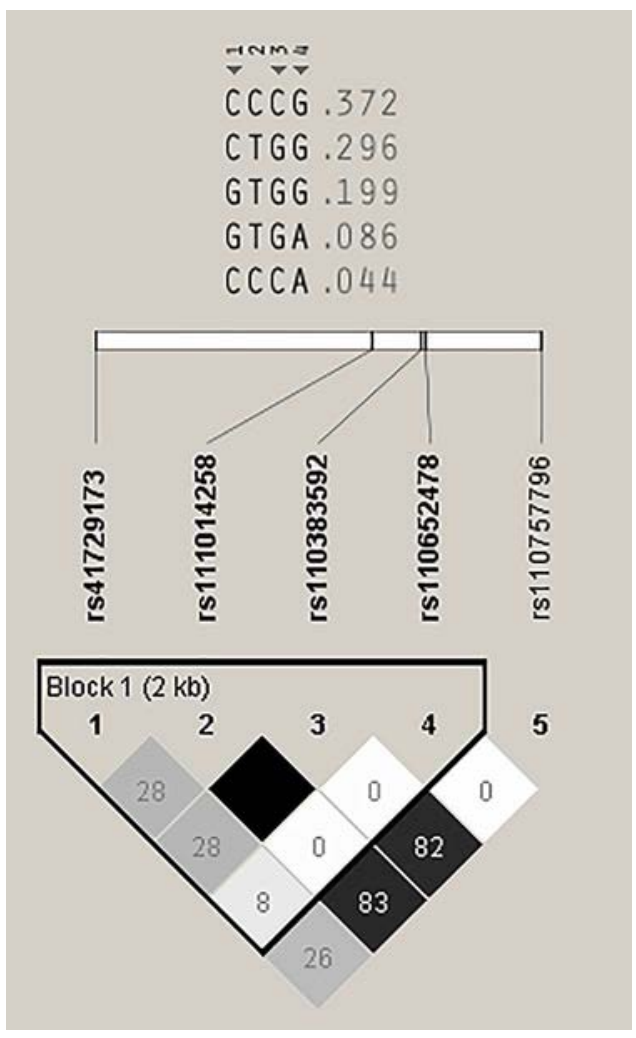

Figure 2. Haplotypes and LD for SNPs rs110652478, rs110757796, rs110383592, rs111014258, and rs41729173 of the bovine FABP4 gene estimated with the solid spine of LD method in an Angus-Hereford-Limousin crossbred population $(\mathrm{N}=260)$. Blocks are indicated with thick lines and $r 2$ values are shown inside the boxes. these associations. The tertiary structure of the bovine FABP4 protein was predicted from a high resolution model of human FABP4 (3q61_A). The tool "compute hydrogen bonds" of the software Swiss-PdbViewer, which considers distance, angle, and atom type, was used to compare interactions among residues of the structures. SNP rs110757796 (Ile74Val) involved residues whose side chains were oriented towards the surface of the protein. This SNP caused small displacements in the proximity of the mutated site, which in turn caused a rearrangement of the hydrogen bonds among residues Thr75, Pro76, Asp77, Asp78, and Arg79 (Fig. S1). In humans, this zone is involved in the interaction with the hydrophobic tail of the ligand through residue 76 . Interestingly, the amino acid change also seemed to block the binding site to the carboxyl group of the ligand by bringing the side chains of Arg127 and Tyr129 together and allowing the formation of a hydrogen bond between them (Fig. S1). These two residues are responsible for the stabilization of the polar group of the ligand through hydrogen bonds and were now forming hydrogen bonds with each other. However, this blockade was not observed when peripheral membrane protein $\mathrm{P} 2$ from human myelin was considered as template for the study. This protein showed the highest score (528.0) in the alignment of HMM profiles provided by the application.

\section{Discussion}

In the re-sequencing study, twenty-two mutations were detected, which resulted in one SNP every 144 bp over a total of 3,164 bp analyzed. When B. taurus and B. indicus were evaluated separately, the diversity rates were one SNP every $151 \mathrm{bp}$ for the Taurine group and one SNP every $452 \mathrm{bp}$ for the Zebuine group. Seven of the 22 SNPs (32\%) were shared by both groups. A few years ago, results from The Bovine Hapmap Consortium (26) 
Table 4. Genotype association with meat quality traits in an Angus-Hereford-Limousin crossbred population.

\begin{tabular}{|c|c|c|c|c|c|c|c|}
\hline SNP/Trait & & east square mear & & Dominance effect & Additive effect & Substitution effect & $\sigma_{S N P}^{2}$ \\
\hline rs41729173 & $\mathrm{CC}(\mathrm{N}=130)$ & CG $(N=109)$ & $\mathrm{GG}(\mathrm{N}=18)$ & & & & \\
\hline MUFA & 47.727 & 47.96 & 48.97 & $-0.381 \pm 0.381(P=0.319)$ & $0.623 \pm 0.306(P=0.043)$ & $(\mathrm{C}>\mathrm{G}) 0.789$ & 0.056 \\
\hline rs110383592 & $\mathrm{GG}(\mathrm{N}=91)$ & $G C(N=120)$ & $\mathrm{CC}(\mathrm{N}=48)$ & & & & \\
\hline C14:1 & $0.509 \pm 0.029$ & $0.557 \pm 0.027$ & $0.468 \pm 0.041$ & $0.069 \pm c$ & $0.020 \pm$ & $(\mathrm{G})$ & 0.860 \\
\hline$\Omega 6 / \Omega 3$ & 3 & & & -0.3 & 0 & 10 & 5.193 \\
\hline BT & $6.852 \pm$ & $6.869 \pm$ & $7.416 \pm 0.227$ & $-0.265 \pm 0.185(P=0.154)$ & $0.282 \pm 0.136(P=0.040)$ & $(G>C) 0.326$ & 1.082 \\
\hline rs110757796 & $A A(N=93)$ & $A G(N=96)$ & $\mathrm{GG}(\mathrm{N}=68)$ & & & & \\
\hline C14:1 & $0.504 \pm 0.028$ & $0.569 \pm 0.029$ & $0.496 \pm 0.035$ & $0.069 \pm 0.032(P=0.035)$ & $0.004 \pm 0$. & $(A>G)-0.003$ & 0.474 \\
\hline BT & $6.841 \pm 0.153$ & $6.801 \pm 0.154$ & $7.458 \pm 0.194$ & $-0.348 \pm 0.183(P=0.059)$ & $0.308 \pm 0.121(P=0.011)$ & $(A>G) 0.342$ & 2.859 \\
\hline
\end{tabular}

Note: N, number of samples; BT, Back fat thickness (mm); C14:1, myristoleic acid content (percentage of total fatty acids); MUFA, total monounsaturated fatty acids content (percentage of total fatty acids); $\Omega 6 / \Omega 3$, ratio of omega- 6 /omega-3 fatty acids. SNP rs 110757796 (missense- exon 2 ) was later analyzed through structural modeling to identify possible causes for the observed effects.

showed one SNP every 714 bp for Angus and Holstein, and one SNP every $285 \mathrm{bp}$ for Brahman. Our rates of variability were much higher for the Taurine group, but lower for the Zebuine group. These results agree with those reported by Cho et al. (20), who detected a total of 15 SNPs in the FABP4 gene in Korean cattle.

High variability was also reflected in the haplotypes and LD analyses, which showed small blocks dispersed along the gene. This may be due to the different historical and geographical origins of the Taurine and Zebuine breeds included in the study or to the high degree of polymorphism in this gene.

The high level of variability observed in FABP4 was similar to that detected by our group in the bovine LIPE gene (21), which encodes an enzyme that interacts with FABP4 in lipid hydrolysis, using the same sample panel. Currently, the SNPdb has more than 95 million polymorphisms for B. taurus, but two thirds of them are yet to be validated and only 11189 show frequency data. These figures remark the importance of performing re-sequencing and SNP validation studies in different cattle breeds. In this sense, the present work allowed the validation of five SNPs in an A-H-L crossbred population fed on pasture.

None of the associations with meat quality traits remained significant after the FDR for multiple comparisons was controlled. However, if we consider individual evaluations, our results are partially consistent with previous reports by other authors. Michal et al. associated SNP rs41729173 (downstream region) with marbling and subcutaneous fat in F2 Wagyu-Limousin crosses (19). Instead, in our population this SNP was associated with total MUFA content. It is worth mentioning that the GG genotype, which was different from the other two, was composed of only 18 animals; therefore, this result should be interpreted with caution. In our study, SNP rs110757796 was associated with BT, as reported by Cho et al. (20). However, instead of the associations with palmitoleic and palmitic acid contents reported by Hoashi et al. (12) and Narukami et al. (14), respectively, we detected an association with myristoleic acid content.
The fact that the heterozygous AG genotype showed higher accumulation is noteworthy and may be explained by different scenarios. One of them may be related with the presence of sufficient binding capability to saturate uptake (provided by allele A) and, at the same time, limit intracellular trafficking destined to processing or releasing the fatty acid (provided by allele G). SNP rs110652478, which was associated with marbling in Korean and Japanese cattle by other authors, behaved differently in our study, as it had no significant effects on the evaluated traits. The association of rs1 10383592 with marbling reported by Barendse et al. (7) and Hoashi et al. (12) was not observed in our sample, but significant effects were observed on myristoleic acid content, omega-6/ omega-3 proportion, and BT. Interestingly, this SNP was linked to rs111014258, which had been previously associated with BT in Korean cattle by Cho et al. (20). Differences between previous reports and our results may be due to racial and environmental differences among populations, experimental designs and definition, and evaluation of the variables employed. In this sense, most of the previous studies were performed under feedlot conditions $(14,20)$; thus, results are not necessarily comparable with those obtained from pasture-based systems. For instance, different diets may activate specific metabolic pathways governed by different genes. Despite partial differences with previous reports, the results obtained here provide additional information about the impact of FABP4 polymorphisms on fatty acid content of meat from pasture-based systems, particularly when most of the exported beef around the world is produced on pasture.

Although several associations have been previously reported in other breeds, none of them involved bioinformatic studies to support such associations. The present study and two others reports $(12,14)$ have found that SNP rs110757796 affected fat content. Since this mutation caused an amino acid change (I74 V) in the ligand binding domain of the protein, it was analyzed through structural modeling to provide a functional explanation to the associations. Results showed that SNP rs110757796 may affect the side chain of 
Arg127, which plays a key role by binding to the carboxylic group of the ligand via hydrogen bonds (27). When the side chain is displaced, the affinity for palmitic acid and other ligands may be affected, especially if Arg127 and Tyr129 form hydrogen bonds with each other, hindering ligand stabilization. Changes in the affinity for certain ligands may alter their transport within the cell, thereby increasing or decreasing their concentration in tissues. A precise view of the interaction between the residues and a molecule of palmitic acid can be observed in model $2 \mathrm{HNX}$ available at PDB. Since this finding is consistent with the results obtained by Hoashi et al. (12) and Narukami et al. (14), who reported associations of this SNP with palmitoleic and palmitic acid contents, respectively, the bioinformatic analyses performed in this study may help explain these results. For instance, Hoashi et al. (12) observed that variant V/V (GG genotype) exhibited a lower palmitoleic acid content than variant I/I (AA genotype), suggesting a decrease in the binding capability of adipocytes for this particular fatty acid, thus lowering uptake and accumulation in muscle adipocytes of Black Japanese cattle. On the other hand, the results obtained in our work showed that variant $\mathrm{V} / \mathrm{V}$ had higher subcutaneous fat thickness than the other two genotypes. Considering that muscle and subcutaneous fat are different tissues, several scenarios may be proposed to explain this effect, since different mechanisms, processes and needs may be operating on these tissues. One of such scenarios may be related with diminished intra-cellular trafficking for processing or releasing fatty acids. Additionally, as European cattle breeds tend to deposit fat in subcutaneous tissues first, uptake may not be affected as much as the other processes due to spontaneous diffusion of fatty acids in the cytoplasm. According to our results, FABP4 may also be involved in the content regulation of myristoleic acid, which has been suggested for treatment of prostate cancer due to its cytotoxic and effective cell death inducer activity (28), and the omega-6/omega-3 ratio, which is related to the pathogenesis of many diseases, including cardiovascular disease, cancer, and inflammatory and autoimmune diseases (29).

As shown in the present work, structural modeling may provide partial explanations, or at least additional information, about the effects of certain missense mutations on an organism, helping to identify desirable or inconvenient mutations according to breeding preferences. This applies for most metabolic pathways regulating economically important traits such as meat quality, puberty and growth. Herein, our results indicate that the effect of rs 110757796 on meat quality traits may be due to a blockage of the ligand binding site of the protein. Although this kind of analysis greatly depends on the availability of previous knowledge about the protein domains and key-residues, it did not represent an obstacle here, as FABP4 is a very-well studied protein given its importance in fat metabolism.

\section{Conclusions}

FABP4 is a highly polymorphic gene. Some polymorphisms may be responsible for changes in meat quality traits, as significant genotype effects were observed in the individual SNP-trait tests, although none of the associations remained significant after adjusting p-values for multiple comparisons. The effects observed here and in other works may be partially explained by structural modifications in key spots of the protein. SNPs should be evaluated in independent populations with in vitro and in vivo analyses to explain the mechanisms by which these polymorphisms would be involved in meat fat content and composition.

\section{Ethical approval}

All animal experiments were carried out in accordance with the U.K. Animals (Scientific Procedures) Act, 1986 and associated guidelines, EU Directive 2010/63/EU for animal experiments, and the National Institutes of Health guide for the care and use of Laboratory animals (NIH Publications No. 8023, revised 1978). All procedures were also in accordance with the ethical standards of CICUAL (Institutional Committee on Care and Use of Experimental Animals) from the School of Veterinary Sciences of the National University of La Plata, Buenos Aires, Argentina.

\section{Acknowledgments}

The authors thank A. Di Maggio for revising and editing the manuscript. DEG is a fellow of CONICET.

\section{Conflict of interest}

The authors declare that they have no conflict of interest.

\section{Funding}

This study was supported by grants from Agencia Nacional de Promoción Científica y Tecnológica (ANPCyT) (PICT 0804156; PICTR2002-0017), Consejo Nacional de Investigaciones Científicas y Técnicas (CONICET) (PIP2010-11220090100379), Instituto Nacional de Tecnología Agropecuaria (INTA) (PNPA1126033; PNCAR-334), Universidad Nacional de Mar del Plata (UNMdP) (AGR456/14; AGR393/12; AGR330/10; AGR270/08; AGR202/05; AGR137/01), and Universidad Nacional de La Plata (UNLP) (ID V206/12, JI 9861/3/11). INTA and UNMdP bred the animals and provided the phenotype records employed 
in the association study. CONICET and UNLP performed the genotype analyses.

\section{References}

1. Shahidi F. Lipid-derived flavors in meat products. In: Kerry J, Kerry J, Ledward D, eds. Meat processing: improving meat quality. Woodhead: Cambridge; 2002: 105-121.

2. Thompson JM. The effects of marbling on flavour and juiciness scores of cooked beef, after adjusting to a constant tenderness. Aust J Exp Agric 2004; 44(7):645-652. http://www.publish.csiro.au/paper/EA02171.

3. Melton SL, Amiri M, Davis GW, Backus WR. Flavor and chemical characteristics of ground beef from grass-, forage-grain- and grain-finished steers. J Anim Sci 1982; 55(1):77-87. doi:10.2134/jas1982.55177x.

4. Mozaffarian $\mathrm{D}$, Ascherio $\mathrm{A}, \mathrm{Hu} \mathrm{FB}$, et al. Interplay between different polyunsaturated fatty acids and risk of coronary heart disease in men. Circulation 2005; 111(2):157-164. doi:10.1161/01.CIR.0000152099.87287.83.

5. Woollett LA, Spady DK, Dietschy JM. Saturated and unsaturated fatty-acids independently regulate lowdensity-lipoprotein receptor activity and production-rate. J Lipid Res 1992; 33(1):77-88.

6. Fortes MRS, Curi RA, Chardulo LAL, et al. Bovine gene polymorphisms related to fat deposition and meat tenderness. Genet Mol Biol 2009; 32(1):75-82. doi:10.1590/S1415-47572009000100011.

7. Barendse W, Bunch RJ, Thomas MB, Harrison BE. A splice site single nucleotide polymorphism of the fatty acid binding protein 4 gene appears to be associated with intramuscular fat deposition in longissimus muscle in Australian cattle. Anim Genet 2009; 40(5):770-773. doi:10.1111/j.1365-2052.2009.01913.x.

8. Maharani D, Jung Y, Jung WY, et al. Association of five candidate genes with fatty acid composition in Korean cattle. Mol Biol Rep 2012; 39(5):6113-6121. doi:10.1007/ s11033-011-1426-6.

9. Kaikaus RM, Bass NM, Ockner RK. Functions of fatty acid binding proteins. Experientia 1990; 46(6):617-630.

10. Duplus E, Glorian M, Forest C. Fatty acid regulation of gene transcription. J Biol Chem 2000; 275(40): 30749-30752. doi:10.1074/jbc.R000015200.

11. Shen W, Liang Y, Hong R, et al. Characterization of the functional interaction of adipocyte lipid-binding protein with hormone-sensitive lipase. J Biol Chem 2001; 276(52):49443-49448. doi:10.1074/jbc.M104095200.

12. Hoashi S, Hinenoya T, Tanaka A, et al. Association between fatty acid compositions and genotypes of FABP4 and LXR-alpha in Japanese black cattle. BMC Genet 2008; 9:84. doi:10.1186/1471-2156-9-84.

13. Lee SH, Werf JHJ, Van Der, Lee SH, et al. Genetic polymorphisms of the bovine Fatty acid binding protein 4 gene are significantly associated with marbling and carcass weight in Hanwoo (Korean Cattle). Anim Genet 2010; 41(4):442-444. doi:10.1111/j.1365-2052.2010.02024.x.

14. Narukami T, Sasazaki S, Oyama K, Nogi T, Taniguchi M, Mannen H. Effect of DNA polymorphisms related to fatty acid composition in adipose tissue of Holstein cattle. Anim Sci J 2011; 82(3):406-411. doi:10.1111/j.1740-0929. 2010.00855.x.
15. Oh DY, Lee YS, La BM, Yeo JS. Identification of the SNP (single nucleotide polymorphism) for fatty acid composition associated with beef flavor-related FABP4 (fatty acid binding protein 4) in Korean cattle. AsianAustralasian J Anim Sci 2012; 25(7):913-920. doi:10.5713/ajas.2012.12078\rajas-25-7-913-2[pii].

16. Shin SC, Heo JP, Chung ER. Genetic variants of the FABP4 gene are associated with marbling scores and meat quality grades in Hanwoo (Korean cattle). Mol Biol Rep 2012; 39(5):5323-5330. doi:10.1007/s11033-011-1331-z.

17. USDA (United States Department of Agriculture). Trade of All Meats to Expand in 2016. Foreign Agricultural Service; 2016. http://apps.fas.usda.gov/psdonline/circulars/ livestock poultry.PDF

18. Giovambattista G, Ripoli M V, Lirón JP, Villegas Castagnasso EE, Peral-García P, Lojo MM. DNA typing in a cattle stealing case. J Forensic Sci 2001; 46(6):1484-1486.

19. Michal JJ, Zhang ZW, Gaskins CT, Jiang Z. The bovine fatty acid binding protein 4 gene is significantly associated with marbling and subcutaneous fat depth in Wagyu $\mathrm{x}$ Limousin F 2 crosses. Anim Genet 2006; 37(4):400-402.

20. Cho S, Park TS, Yoon D, et al. Identification of genetic polymorphisms in FABP3 and FABP4 and putative association with back fat thickness in Korean native cattle. BMB Rep 2008; 41(1):29-34.

21. Goszczynski DE, Mazzucco JP, Ripoli MV, et al. Characterization of the bovine gene LIPE and possible influence on fatty acid composition of meat. Meta Gen 2014; 2:746-760. doi:10.1016/j.mgene.2014.09.001.

22. Barrett JC, Fry B, Maller J, Daly MJ. Haploview: analysis and visualization of $\mathrm{LD}$ and haplotype maps. Bioinformatics 2005; 21(2):263-265. doi:10.1093/bioinformatics/ bth457.

23. Benjamini Y, Hochberg Y. Controlling the false discovery rate: a practical and powerful approach to multiple testing. J R Stat Soc B 1995; 57(1):289-300. doi:10.2307/ 2346101.

24. Falconer DS, Mackay TFC. Introduction to quantitative genetics, 4th edn. Harlow Essex, UK: Addison Wesley Limited, Edinburg Gate; 1996.

25. Biegert A, Lupas AN. The HHpred interactive server for protein homology detection and structure prediction. Nucleic Acids Res 2005; 33:244-248. doi:10.1093/nar/ gki408.

26. Bovine HapMap Consortium, Gibbs RA, Taylor JF, et al. Genome-wide survey of SNP variation uncovers the genetic structure of cattle breeds. Science 2009; 324(5926):528-532. doi:10.1126/science.1167936.

27. Marr E, Tardie M, Carty M, et al. Expression, purification, crystallization and structure of human adipocyte lipidbinding protein (aP2). Acta Crystallogr Sect F Struct Biol Cryst Commun 2006; 62(11):1058-1060. doi:10.1107/ S1744309106038656.

28. Iguchi K, Okumura N, Usui S, Sajiki H, Hirota K, Hirano K. Myristoleic acid, a cytotoxic component in the extract from Serenoa repens, induces apoptosis and necrosis in human prostatic LNCaP cells. Prostate 2001; 47(1):59-65. doi:10.1002/pros.1047.

29. Simopoulos AP. The importance of the ratio of omega-6/ omega-3 essential fatty acids. Biomed Pharmacother 2002; 56(8):365-379. 